\title{
Major liver surgery in a Jehovah's Witness patient: challenges for safe surgery
}

\author{
WY Lim, ${ }^{1 *}$ L Loh, ${ }^{1}$ Suneel R Desai, ${ }^{1}$ SL Tien, ${ }^{2}$ BK Goh, ${ }^{3}$ P Wong' \\ ${ }^{1}$ Department of Anaesthesiology, Singapore General Hospital \\ ${ }^{2}$ Department of Haematology, Singapore General Hospital \\ ${ }^{3}$ Department of Hepatopancreatobiliary and Transplant Surgery, Singapore General Hospital \\ *Corresponding author, email: lim.wan.yen@singhealth.com.sg
}

Jehovah's Witnesses presenting for major surgery run the risk of major bleeding, which is complicated by the refusal to accept blood transfusion. We present a case of a 63-year-old woman, a Jehovah's Witness, who was diagnosed with hepatocellular carcinoma and advised for curative laparoscopic liver segmentectomy. Due to the risk of significant intraoperative haemorrhage, her perioperative care was coordinated in a multidisciplinary manner. Informed consent requires the physician to advise on the material risks of undertaking major surgery without blood transfusion and the possible alternatives. Conflicting ethical issues of patient autonomy and beneficence related to refusal of blood products also arise. Perioperative strategies to minimise blood loss, maximise haematopoiesis and tolerance of anaemia to facilitate safe surgery in such patients are also presented.

Written patient consent obtained.

Keywords: Jehovah Witness, perioperative anaemia, patient blood management, consent, general anaesthesia

\section{Case description}

A 63-year-old female was admitted for acute onset epigastric pain and vomiting. She weighed $42 \mathrm{~kg}$ and her medical history included diabetes mellitus and hyperlipidaemia. Investigations revealed a lesion $(2.6 \times 2.5 \times 2.1 \mathrm{~cm})$ in segment IVb of the liver and a provisional diagnosis of focal hepatocellular carcinoma was made. A joint decision for a potentially curative laparoscopic hepatectomy was offered.

The patient identified herself as a Jehovah's Witness for the first time in the preoperative anaesthesia clinic ten days before her scheduled surgery. She attended clinic with a family member and presented her advanced medical directive then. Her medications included metformin, glipizide and simvastatin. She was advised to stop taking chinese herbal supplements due to the potential increased risk of bleeding. Investigations revealed a haemoglobin of $13.8 \mathrm{~g} / \mathrm{dL}$, a platelet count of $376 \times 10^{9} /$, normal serum biochemistry, liver function tests, iron studies and hepatitis tests. She was started on oral ferrous fumarate 200 mg twice daily and, after discussions with the haematologist, erythropoietin was deemed unnecessary.

A preoperative multidisciplinary team (MDT) meeting involving the medical team (surgeon, anaesthesiologist, haematologist), the patient, and her family/church members took place two days later. Our discussions were based on a modified "Jehovah's Witness Consent/Release" form* by the AAGBI. After detailed explanation of the options, the patient accepted albumin, recombinant clotting factor VIla and acute normovolaemic haemodilution (ANH). Her consent form explicitly stated that she "expressly withholds consent" for all other transfusion products "and will not be overridden in any circumstances" even if lifethreatening. The patient was informed regarding an estimated blood loss of $500 \mathrm{ml}$ and a $5 \%$ risk of perioperative mortality compared to $<1 \%$ in the standard patient. We also provisionally booked a postoperative intensive care bed. One day prior to surgery, her haemoglobin was $14.5 \mathrm{~g} / \mathrm{dl}$.

Prior to the surgery, she was spoken to alone to confirm her refusal for blood products. This allowed the patient time to assimilate the information conveyed and made the decision for refusal of blood products in the absence of family or church members. All operating theatre personnel were informed of the specific requirements during the team brief. Standard monitoring was applied and a 16G intravenous cannula was inserted. General anaesthesia was induced with propofol $100 \mathrm{mg}$, fentanyl 100 $\mathrm{mcg}$, rocuronium $60 \mathrm{mg}$, remifentanil infusion and her trachea intubated with a $7.5 \mathrm{~mm}$ tracheal tube. Anaesthesia was maintained by desflurane in an oxygen/air mixture. $400 \mathrm{ml}$ of autologous blood was drained into a citrated blood-donor bag, kept in continuity with the patient. $500 \mathrm{ml}$ Hartmann's solution was then infused to maintain normovolaemia. Additional monitoring including oesophageal temperature probe, invasive arterial and central venous pressure lines, and urinary catheter were established. An arterial blood gas analysis showed haemoglobin $10.2 \mathrm{~g} / \mathrm{dL}$. Measures to maintain normothermia included warmed fluids administration and forced air warming mattress. Intravenous tranexamic acid $1 \mathrm{~g}$ was administered.

Meticulous surgical haemostasis was ensured using on-table ultrasound localisation of the tumour, the Cavitron Ultrasonic Surgical Aspirator (CUSA', Tyco Healthcare, USA) for tissue dissection and LigaSure ${ }^{\mathrm{TM}}$ (Valley Lab, Tyco Healthcare, USA) for 
vessel sealing. Surgery lasted approximately two hours with an estimated $250 \mathrm{ml}$ blood loss. Fluid therapy was titrated based on clinical status including haemodynamic status and urine output. The patient received two litres of crystalloids and a recheck haemoglobin was $9.9 \mathrm{~g} / \mathrm{dL} .400 \mathrm{ml}$ of autologous blood was administered. The patient was monitored in the highdependency unit postoperatively. Her haemoglobin the next day was $12.4 \mathrm{~g} / \mathrm{dl}$. She made an uneventful recovery and was discharged home on the third postoperative day.

\section{Discussion}

\section{Overview}

The Jehovah's Witness religion is an active Christian movement founded in 1881 with eight million members worldwide. The religion is banned in various countries, on the grounds that its followers refuse to perform compulsory military service or swear allegiance to the state.**

Jehovah's Witnesses will consent for medical intervention and surgery, but typically not for transfusion of whole blood, red cells, white cells, platelets and plasma. The rationale is that blood represents life and its sanctity must be respected, and so transfusion of allogeneic blood is forbidden. Other blood components and extracorporeal procedures (e.g. ANH, cellsalvage, cardiopulmonary bypass and extracorporeal membrane oxygenation) may be deemed acceptable but interpretation varies.

In recent literature, safe transfusion triggers have been lowered, as clinical outcomes are similar with a haemoglobin level of 7-8 $\mathrm{g} / \mathrm{dl}$ compared with $10 \mathrm{~g} / \mathrm{dll}^{2}$ Elective surgery with a preoperative haemoglobin of $6 \mathrm{~g} / \mathrm{dL}$ has been reported; however, perioperative mortality increases with blood loss $>500$ $\mathrm{ml}$ irrespective of the preoperative haemoglobin concentration. ${ }^{3}$ The risk of mortality and/or morbidity also rises significantly if haemoglobin level falls below $5-6 \mathrm{~g} / \mathrm{dL}^{4}{ }^{4}$

\section{Legal, ethical and psychological considerations}

The management of Jehovah's Witnesses presents legal, ethical and psychological challenges. Legally, a valid consent requires a patient with mental capacity to exercise a choice and be appropriately informed about the intervention and options. ${ }^{5}$ This must include the risks and benefits of anaemia and transfusion, and the adjusted risk if blood transfusion is refused. Previously, medical care, including disclosure of information regarding risks, has been doctor-centred as per the 'Bolam' principle. ${ }^{6}$ The 'Bolam' principle is a measure of whether one has discharged the standard of care in the management of the patient. A patient-centred approach is now adopted to "ensure that the patient is aware of any material risks involved in any recommended treatment, and of any reasonable alternatives".6 With reference to the recent Montgomery landmark case in the UK where pertinent risks to the patient should be disclosed, in this case, risks arising from surgery in the presence of anaemia, potential bleeding, along with an exclusion of blood transfusion should be discussed with Jehovah's Witnesses. ${ }^{7}$ Our institution's anaesthesia and blood consent forms do not specifically include refusal of blood transfusion. Following this case, our institution created and introduced a "refusal of blood transfusion" form for relevant patients.

The medical ethical dilemmas of managing a Jehovah's Witness patient include: respect for patient's autonomy; beneficence; nonmaleficence; and justice. ${ }^{8}$ However, these principles may conflict with each other and be open to interpretation. ${ }^{9}$ Ultimately, the law and medical governing bodies favour the principle of autonomy. ${ }^{1,9-13}$ Giving blood to an adult with capacity who has explicitly refused is unlawful and ethically unacceptable.

There are also psychological issues involved as restrictions on the doctor's clinical freedom may cause considerable stress, especially when there is a risk of (avoidable) death. Doctors have the right to refuse in an elective situation but should attempt to refer to a colleague comfortable treating Jehovah's Witnesses and their increased risks. ${ }^{1}$

\section{Perioperative management}

Managing Jehovah's Witnesses requires a MDT approach: formulating the perioperative management, establishing the Jehovah's Witnesses status, clarifying personal beliefs and wishes, and obtaining informed consent. An advanced directive, if available must be signed and witnessed, with clear and explicit refusal of blood and blood components.' There should be an opportunity to discuss issues frankly with the patient alone, to avoid undue influence by family or church members. The meeting should occur several weeks in advance to allow time for patient consideration, including revoking consent, and also enables preoperative optimisation of haemoglobin. These meetings have led to positive feedback from both patients and clinicians. ${ }^{12,14}$ In this case, the multidisciplinary teams deemed the patient optimised for operation without any need to postpone the operation. However, in other cases where patient requires further optimisation, operation postponement may be necessary. If the patient changes his/her mind about blood transfusion at any time, this should be documented and communicated. Patient confidentiality must be maintained and measures include blood transfusion out of visiting hours.

Preoperatively, phlebotomy is kept to a minimum and paediatric blood bottles should be used. Pre-existing causes of anaemia are investigated and treated. When treating anaemia preoperatively, the target haemoglobin concentration should be $\geq 13 \mathrm{~g} / \mathrm{dL}$ in both genders. ${ }^{15}$ Oral iron is beneficial if initiated 6-8 weeks before surgery but may cause gastrointestinal side-effects. Intravenous iron is well-tolerated and generates a faster haemoglobin response (two weeks). ${ }^{16}$ In our patient

** https://www.state.gov/j/drl/rls/irf/2001/5732.htm 
with normal haemoglobin level and iron studies, intravenous iron replacement was not necessary. However, oral iron supplementation was commenced based on recommendation by the haematologist, in anticipation of intraoperative blood loss. Recombinant erythropoietin stimulates erythropoiesis within one to six weeks ${ }^{11}$ but is ineffective in patients with iron, vitamin B12 and folate deficiencies, so these should be treated. Erythropoietin is avoided if haemoglobin $>13 \mathrm{~g} / \mathrm{dL}$ due to the risk of thrombosis, and is contraindicated in uncontrolled hypertension, recent myocardial infarction or cerebrovascular accident, unstable angina or a history of thrombosis. ${ }^{13}$ Drugs or supplements that increase the risk of bleeding (e.g. nonsteroidal anti-inflammatory drugs, garlic) should be discontinued. Antiplatelet agents and anticoagulants may need to be stopped and/or pharmacologically reversed. Preoperative shrinkage and/ or devascularisation of tumours should be considered.

Just before the start of the surgery, a team brief is held as part of the surgical safety checklist. This should include a plan for emergency management of haemorrhage and damage-control strategies. ${ }^{13}$ There are various intraoperative strategies to reduce bleeding. ${ }^{1,11,14}$ Anaesthetic techniques include: hypotensive anaesthesia ${ }^{17,18}$; maintenance of normothermia; correction of abnormal coagulation; and the use of regional anaesthesia ${ }^{19}$ which allows patients to reconsider blood transfusion if a lifethreatening haemorrhage occurs. ANH involves the removal of blood, followed by rapid fluid replacement (crystalloid or colloid) to attain normovolaemia. ${ }^{12}$

Surgical techniques include: surgical positioning; meticulous haemostasis; use of haemostatic-dissecting devices and tourniquet; minimally-invasive techniques; and staging complex operations. Haemostatic agents may be topical (e.g. surgical glues/sealants) or intravenous (e.g. tranexamic acid, clotting factors). Techniques specific to liver resection include realtime tumour localisation using ultrasound, CUSA for tissue dissection, use of the "pringle" manoeuvre, maintenance of low central venous pressures and controlled hypotension including use of venodilators e.g. glyceryl trinitrate, judicious fluid management, minimising positive end-expiratory pressure, use of neuromuscular blocker to avoid high intrathoracic pressures and increasing inspiratory:expiratory time ratio.

Alternatives to blood transfusion include cell-salvage and artificial oxygen carriers. Re-infusion of salvaged blood from patients with cancer has not led to tumour dissemination or metastases. ${ }^{20}$ Recombinant Factor VIla can be given under "off label" use for severe, uncontrollable bleeding during surgery. ${ }^{21}$

\section{Conclusion}

Jehovah's Witness patients present unique medical, legal and ethical challenges when presenting for surgery. These patients should be managed by a MDT with a patient-centric approach, explaining the risks of undertaking surgery without blood transfusion and respect for the patient's beliefs. A rigorous consent process, multi-disciplinary team-based preoperative optimisation and meticulous intraoperative technique and haemostasis are key to favourable outcomes in this group of patients.

\section{References}

1. Management of anaesthesia for Jehovah's Witnesses - aagbi. Available from: https://www.aagbi.org/sites/default/files/Jehovah's\%20Witness\%201999.pdf

2. Goodnough LT, Shander A. Patient blood management. Anesthesiology 2012;116(6):1367-76.

3. Spence RK, Carson JA, Poses R, McCoy S, Pello M, Alexander J, et al. Elective surgery without transfusion: influence of preoperative hemoglobin level and blood loss on mortality. Am J Surg 1990;159(3):320-4.

4. Carson JL, Noveck H, Berlin JA, Gould SA. Mortality and morbidity in patients with very low postoperative $\mathrm{Hb}$ levels who decline blood transfusion. Transfusion 2002;42(7):812-8.

5. Yentis SM, Hartle AJ, Barker IR, Barker P, Bogod DG, Clutton-Brock TH, et al. AAGBI: Consent for anaesthesia 2017. Anaesthesia 2017;72(1):93-105.

6. Lee A. "Bolam" to "Montgomery" is result of evolutionary change of medical practice towards "patient-centred care." Postgrad Med J 2017:93(1095):46-50.

7. Montgomery (Appellant) $v$ Lanarkshire Health Board (Respondent). Available from: https://www.supremecourt.uk/decided-cases/docs/UKSC_2013_0136 Judgment.pdf

8. Gillon R. Medical ethics: four principles plus attention to scope. BM 1994;309(6948):184-8.

9. Macklin R. Applying the four principles. J Med Ethics 2003;29(5):275-80.

10. Chua R, Tham KF. Will "no blood" kill Jehovah Witnesses? Singapore Med J 2006;47(11):994-1001; quiz 1002.

11. Lawson T, Ralph C. Perioperative Jehovah's Witnesses: a review. Br J Anaesth 2015;115(5):676-87.

12. Marsh JCW, Bevan DH. Haematological care of the Jehovah's Witness patient. Br J Haematol 2002;119(1):25-37.

13. Caring for patients who refuse blood. Royal College of Surgeons. Available from: https://www.rcseng.ac.uk/-/media/files/rcs/library-and-publications/ non-journal-publications/caring-for-patients-who-refuse-blood--a-guide-togood-practice.pdf

14. Rollins KE, Contractor U, Inumerable R, Lobo DN. Major abdominal surgery in Jehovah's Witnesses. Ann R Coll Surg Engl 2016;98(8):532-7.

15. Muñoz $M$, Acheson AG, Auerbach $M$, Besser $M$, Habler $O$, Kehlet $H$, et al. International consensus statement on the peri-operative management of anaemia and iron deficiency. Anaesthesia 2017;72(2):233-47.

16. Goodnough LT, Skikne B, Brugnara C. Erythropoietin, iron, and erythropoiesis. Blood 2000;96(3):823-33.

17. Paul JE, Ling E, Lalonde C, Thabane L. Deliberate hypotension in orthopedic surgery reduces blood loss and transfusion requirements: a meta-analysis of randomized controlled trials. Can J Anaesth 2007:54(10):799-810.

18. Ervens J, Marks C, Hechler M, Plath T, Hansen D, Hoffmeister B. Effect of induced hypotensive anaesthesia vs isovolaemic haemodilution on blood loss and transfusion requirements in orthognathic surgery: a prospective, single-blinded, randomized, controlled clinical study. Int J Oral Maxillofac Surg 2010;39(12):1168-74.

19. Richman JM, Rowlingson AJ, Maine DN, Courpas GE, Weller JF, Wu CL. Does neuraxial anesthesia reduce intraoperative blood loss? A meta-analysis. J Clin Anesth 2006;18(6):427-35.

20. Zaw AS, Bangalore Kantharajanna S, Kumar N. Is autologous salvaged blood a viable option for patient blood management in oncologic surgery? Transfus Med Rev 2017;31(1):56-61.

21. Tanaka A, Ota T, Uriel N, Asfaw Z, Onsager D, Lonchyna VA, et al. Cardiovascular surgery in Jehovah's Witness patients: The role of preoperative optimization. J Thorac Cardiovasc Surg 2015;150(4):976-83.e1-3. 